\title{
BMJ Open Psychosocial volunteer support for older adults with cognitive impairment: development of MyCare Ageing using a codesign approach via action research
}

\author{
Darshini Ayton (D) , ${ }^{1,2}$ Renée O'Donnell (D) , ${ }^{1}$ Dave Vicary, ${ }^{3}$ Catherine Bateman, ${ }^{4}$ \\ Chris Moran, ${ }^{5}$ Velandai K Srikanth, ${ }^{5}$ Julie Lustig, ${ }^{6}$ Jane Banaszak-Holl, ${ }^{2}$ \\ Peter Hunter, ${ }^{7}$ Elizabeth Pritchard, ${ }^{2}$ Heather Morris, ${ }^{1}$ Melissa Savaglio, ${ }^{1}$ \\ Seema Parikh, ${ }^{8}$ Helen Skouteris ${ }^{1,9}$
}

To cite: Ayton D, O'Donnell R, Vicary D, et al. Psychosocial volunteer support for older adults with cognitive impairment: development of MyCare Ageing using a codesign approach via action research. BMJ Open 2020;10:e036449. doi:10.1136/ bmjopen-2019-036449

- Prepublication history and additional material for this paper is available online. To view these files, please visit the journal online (http://dx.doi.org/10. 1136/bmjopen-2019-036449).

Received 17 December 2019 Revised 17 August 2020 Accepted 24 August 2020

Check for updates

(c) Author(s) (or their employer(s)) 2020. Re-use permitted under CC BY-NC. No commercial re-use. See rights and permissions. Published by BMJ.

For numbered affiliations see end of article.

Correspondence to Professor Helen Skouteris; helen.skouteris@monash.edu

\section{ABSTRACT}

Background and objectives Older adults with cognitive impairment are vulnerable to frequent hospital admissions and emergency department presentations. The aim of this study was to use a codesign approach to develop MyCare Ageing, a programme that will train volunteers to provide psychosocial support to older people with dementia and/ or delirium in hospital and at home when discharged from hospital.

Setting Melbourne, Victoria, Australia.

Research design This study adopts an action research methodology. We report on two co-design workshops with keystakeholders: Workshop 1: identification of components from three existing programmes to inform the development of the MyCare Ageing program logic and, Workshop 2: identification of implementation strategies.

Participants The key stakeholders and workshop participants included clinicians (geriatricians, nurses and allied health), hospital staff (volunteer coordinators and hospital executives), Baptcare staff, a consumer, researchers and implementation experts and project staff. Results Workshop 1 identified the components from three existing programmes - the Volunteer Dementia and Delirium Care programme, Home-Start and MyCare for inclusion in MyCare Ageing. In workshop 2 , the $p$ implementation plan was developed taking into consideration hospital-specific processes, training and support needs of volunteers and safety and risk management processes.

Discussion and conclusion The codesign process was successfully applied to develop the MyCare Ageing programme to provide volunteer support to patients with dementia and/or delirium in hospital and their transition home. MyCare Ageing is an innovative programme that meets an identified need from hospitals and consumers to support patients with dementia and/or delirium to improve psychosocial outcomes on discharge from hospital.

\section{BACKGROUND}

Current health system care models do not meet the needs of high-risk older people, leading to frequent hospital and emergency
Strengths and limitations of this study

- This study adopts a robust action research approach involving key stakeholders, including a consumer, to develop MyCare Ageing.

- Identification of key stakeholders was based on word of mouth and purposive sampling and hence some stakeholders may have been overlooked.

- MyCare Ageing has been developed based on three existing programmes that have been successfully implemented and evaluated.

- MyCare Ageing has been developed using a programme logic framework.

- Perceived barriers and enablers and strengths and limitations to the implementation of MyCare Ageing were identified using the capability, opportunity and motivation for behaviour change framework and a strengths, weaknesses, opportunities and threats analysis.

department visits, increased hospital readmissions and poor outcomes. ${ }^{1}$ People aged over 65 years are increasingly the most represented patient group in the acute care system-a system organised on curative episodic care. ${ }^{2}{ }^{3}$ Older adults typically have multiple comorbidities and complex social needs, which current acute care health systems are not equipped to address holistically. ${ }^{4}$ Healthcare systems tend to focus on physical health, even though psychological and social impacts including loneliness and inactivity were identified as issues of concern for frail older patients 1 week postdischarge. ${ }^{5}$ It is, therefore, not surprising that one in five older patients are at risk of readmission to an acute hospital within 30 days of discharge. ${ }^{5}$

Internationally, governments are investing in models of care to keep older adults, and particularly those with dementia, out of 
hospital. ${ }^{1}$ Examples of innovative models of care include specialised emergency department units for the elderly, ${ }^{67}$ telehealth follow-up postdischarge ${ }^{8}$ and transitional care nurses. ${ }^{9}$ These models are staff and resource intensive and may not be accessible or sustainable for all health services. We sought to address these issues by developing MyCare Ageing, a volunteer-delivered intervention to provide psychosocial support to older people with dementia or delirium (or at risk of delirium) in hospital and their transition home; this paper describes the codesign development process for MyCare Ageing.

\section{Hospital volunteer programmes}

To overcome staff and resource barriers, volunteer programmes have been implemented to provide necessary and meaningful non-medical care for older patients. ${ }^{10-14}$ The American Hospital Association has stated that hospital volunteers 'stand out as key contributors in the success of pursuing the Triple Aim - improving the patient experience of care, improving the health of populations and reducing the per-capita cost of healthcare' (pp. 4, 13). The value of volunteers is illustrated with the Hospital Elder Life Program (HELP) and the Fam-HELP programme, in which volunteers deliver interventions to prevent delirium. Serving more than 7000 patients in six large US hospitals in $2011,{ }^{12}$ volunteers ensured the patient could see, hear and eat with appropriate aids, oriented the patient and provided companionship. The impact of HELP, demonstrated via randomised controlled trials, includes reduced rates of delirium, length of stay, hospital costs and increased satisfaction of patients, families and nursing staff. ${ }^{12}$

Volunteer support provided to persons with delirium or dementia in the hospital setting is associated with many positive outcomes. However, these programmes consistently end their relationship with the patients once they transition home, even though research shows persons with delirium or dementia find this transitional process stressful due to the fragmentation of care, ineffective coordination between service providers, communication breakdowns and insufficient patient and caregiver preparation. ${ }^{15}$ A programme that provides both hospital and transitional support is needed, yet it is our understanding that such programme does not exist.

The MyCare Ageing programme aims to provide psychosocial support to older adults with dementia and/ or delirium and to assist with problem-solving challenges and facilitate access to community services postdischarge that could ameliorate transition issues and prevent hospital readmissions.

In this paper, we describe the codesign process for the MyCare Ageing programme. Codesign refers to the voluntary involvement of patients, carers, staff and stakeholders in the design, management, delivery and evaluation of a particular service. ${ }^{16}$ Codesign offers several benefits to both consumers of the programme (ie, increased satisfaction and improved outcomes) ${ }^{17}$ and staff and organisations that deliver the programme (ie, a better understanding of client needs, improvements in staff well-being and increased service effectiveness).${ }^{18}$ Therefore, this process was adopted in the present study to ensure the knowledge of key stakeholders was harnessed and embedded accordingly into MyCare Ageing.

The specific objectives of this study were as follows:

1. To codesign with key stakeholders the MyCare Ageing programme.

2. To identify strengths, weaknesses, opportunities and threats for implementing the proposed MyCare Ageing programme.

3. To examine the perceived barriers to and enablers of the MyCare Ageing programme's implementation from the perspective of key stakeholders.

\section{METHODS}

The overall project was a mixed methods action research study conducted in Melbourne, Australia. The project follows a seven-step cycle (see table 1 below). In this paper, we report on step one (identifying and limiting the topic) and two (determining the research, intervention or action plan), which used codesign methodology.

\section{Description of the research team}

The investigator team consists of implementation and health services researchers (HS, DA and JB-H), geriatricians (CM, VKS, JL, SP and PH), nursing and the Volunteer Dementia and Delirium Care (VDDC) Program developer (CB) and non-profit and community services (DV). The project team included clinical research fellows (psychology and allied health) (RO, HM, MS and EP). The project team have an ongoing collaboration to work through the remaining steps of the Action Research Cycle (steps 3-7).

\section{Workshop 1: identification of MyCare Ageing programme components}

The objective of workshop one was to develop MyCare Ageing. Based on the previous work and experience of the investigator team, three evidence-based programmes currently being delivered in Australia were identified to guide the development of MyCare Ageing: VDDC, HomeStart and MyCare. These programmes were chosen due to the following attributes: practice led, successful uptake by consumers and relevant to hospital and community settings. The previous literature, implementation studies and evaluations of these programmes were accessed via the programme developers and evaluators.

\section{Recruitment}

Email invitations were sent by the project team (EP, DA, RO and DV) to identified key stakeholders. Twenty-two people in addition to the investigators were invited to participate in a 5-hour workshop.

\section{Workshop overview}

Workshop 1 commenced with an overview of the purpose of the day, the aims of MyCare Ageing and introductions 
Table 1 Seven step mixed methods action research adopted in MyCare Ageing

Step

2. Determining the research, intervention and action plan*

\section{Administer the intervention and collection} appropriate data such as measures, observations and interviews

\section{Research methods}

A multidisciplinary investigator team identified the problem - the need to provide psychosocial support to older adults in hospital and in the transition home to reduce hospital readmissions, poor quality of life and hospital adverse events. The three existing programmes-MyCare, Home-Start and the Volunteer Dementia and Delirium Care programme-identified and included in the research were reviewed by the investigator team for inclusion. This review included preimplementation research and evaluations to determine scope, impacts and applicability.

Two codesign workshops with clinicians, hospital staff, volunteer coordinators, implementation researchers and a consumer to develop the programme logic and implementation plan for MyCare Ageing.

Training of volunteers through Baptcare and hospitals.

Implementation of MyCare Ageing in hospitals and in the community. Process evaluation of implementation to assess implementation fidelity, acceptability and feasibility.

Data collection of patient outcomes, hospital outcomes, volunteer experiences, patient and caregiver experiences and hospital staff experiences.

\section{Data analysis}

Qualitative and quantitative data from phase 3 implementation will be triangulated to determine programme impacts and experiences.

Investigator team and key project stakeholders to review data analysis from step 4 and identify modifications to MyCare Ageing.

Modifications to MyCare Ageing recorded with programme logic and implementation plan updated.

Steps 3-6 to be written up and submitted for publication.

7. Write up and dissemination

Steps 3-6 to be written up and submitted for publication.

*Steps reported in this study.

of each workshop participant (DA). Following this, a representative from each of the three programmes (table 2) presented on the programme components.

\section{The VDDC programme (CB)}

The VDDC programme was originally implemented as a pilot study at one rural New South Wales (NSW) hospital in 2009. ${ }^{10}$ The NSW Agency for Clinical Innovation subsequently funded the development of a VDDC Implementation and Training Resource. ${ }^{19}$ The programme recruits and trains volunteers to provide person-centred, oneto-one emotional and practical support (eg, assisting with eating and drinking, supporting safe walking, promoting the use of visual/hearing aids and engagement in therapeutic activities) to reduce risk and improve the physical and emotional well-being of hospital patients with cognitive impairment (dementia and/or delirium). The volunteer role is seen as similar to that of a family carer. Evaluations of the VDDC programme in seven rural NSW hospitals demonstrated a reduction in 28-day readmissions and patient sitters (Blair, Anderson, \& Bateman, 2018). ${ }^{20}$ Caregiver and staff reported improved patient safety, nutrition, hydration and reduced patient distress. ${ }^{20}$ The VDDC programme was developed in rural hospitals in NSW, Australia.

In 2017, preimplementation studies conducted by Ayton and colleagues (2019) ${ }^{21} 22$ explored the acceptability and barriers and enablers of implementing the VDDC programme into a large metropolitan hospital in Melbourne. Nurses, geriatricians, volunteers, hospital key stakeholders and patient and carers participated. Participants were enthusiastic about the programme and recognised volunteer support would improve patient and caregiver experiences of care. However, there were concerns about hospital resources to support and coordinate the volunteers and some participants expressed concern with volunteers undertaking activities such as feeding and mobilisation. ${ }^{2122}$

\section{Baptcare programmes}

Baptcare-a large not-for-profit organisation-coordinates the MyCare and Home-Start programmes in Victoria and Tasmania, Australia. Baptcare designed MyCare, an outreach service for people aged 18-64 years with severe or persistent mental illness. The programme is client-driven, strengths-based and delivers psychosocial support tailored to the needs of the client. Home-Start was established in the UK and provides volunteer homevisiting support through mentoring and practical support for vulnerable families.

\section{MyCare (DV)}

MyCare was developed in partnership with the Department of Health and Human Services, in Tasmania in 
Table 2 Overview of the three programmes guiding the development of MyCare Ageing

\begin{tabular}{|c|c|c|c|}
\hline Programme & VDDC programme & Home-Start & MyCare \\
\hline Aim & $\begin{array}{l}\text { To provide emotional support and practical assistance } \\
\text { to vulnerable patients with dementia and delirium or } \\
\text { those patients with identified risk factors for delirium and } \\
\text { reduce their risk of adverse outcomes. }\end{array}$ & $\begin{array}{l}\text { To support disadvantaged } \\
\text { families with children aged } 5 \\
\text { years and under. }\end{array}$ & $\begin{array}{l}\text { To provide a client-driven, } \\
\text { strengths-based and } \\
\text { psychosocial support to } \\
\text { clients with severe mental } \\
\text { health issues. }\end{array}$ \\
\hline $\begin{array}{l}\text { Target } \\
\text { population }\end{array}$ & $\begin{array}{l}\text { Older adults } 65+\text { years with dementia and/or delirium or } \\
\text { risk of delirium. }\end{array}$ & $\begin{array}{l}\text { Families that are experiencing } \\
\text { disadvantage and have a } \\
\text { child aged } 5 \text { years and under. }\end{array}$ & $\begin{array}{l}\text { People aged } 18-64 \text { years } \\
\text { with severe or persistent } \\
\text { mental illness. }\end{array}$ \\
\hline Delivery mode & Trained volunteers in acute hospital. & $\begin{array}{l}\text { Home visitations by trained } \\
\text { volunteers. }\end{array}$ & $\begin{array}{l}\text { Home visitations by paid } \\
\text { workers. }\end{array}$ \\
\hline $\begin{array}{l}\text { Programme } \\
\text { activities }\end{array}$ & $\begin{array}{l}\text { Creating a person-centred profile for the patient. } \\
\text { One-on-one emotional care and support } \\
\text { Therapeutic activities: massage, games and reading. } \\
\text { Assisting with and promoting hydration and nutrition. } \\
\text { Walking with patients if safe. } \\
\text { Assisting with vision and hearing aids. } \\
\text { Supporting sleep and rest. } \\
\text { Supporting orientation. }\end{array}$ & $\begin{array}{l}\text { Outreach support to facilitate } \\
\text { parenting skills and family } \\
\text { coping mechanism. }\end{array}$ & $\begin{array}{l}\text { Step down assertive } \\
\text { outreach support with a } \\
\text { dual-focus of both mental } \\
\text { health and psychosocial } \\
\text { issues. }\end{array}$ \\
\hline $\begin{array}{l}\text { Implementation } \\
\text { activities }\end{array}$ & $\begin{array}{l}\text { A hospital volunteer programme implementation } \\
\text { guide. } \\
\text { Forms and templates to assist with implementation. } \\
\text { Staff and volunteer procedures and resources for } \\
\text { individual service adaptation. } \\
\text { Forms and templates for procedural components of } \\
\text { the programme. } \\
\text { A facilitator training manual with resources required } \\
\text { for running an eight session group volunteer training } \\
\text { programme. } \\
\text { Handouts and PowerPoint presentations. } \\
\text { Dementia and delirium care volunteer training DVD. } \\
\text { The seven chapters in the DVD are aligned with the } \\
\text { group training sessions. } \\
\text { Dementia and Delirium Care Volunteer DVD Training } \\
\text { Handbook with additional volunteer reading. } \\
\text { https://www.aci.health.nsw.gov.au/resources/aged- } \\
\text { health/confused_hospitalised_older_persons/dementia- } \\
\text { and-delirium-care-implementation-training }\end{array}$ & & $\begin{array}{l}\text { Using the resource } \\
\text { sharing agreement, care } \\
\text { coordinators work closely } \\
\text { with case managers to } \\
\text { capture and share local } \\
\text { knowledge regarding the } \\
\text { client's progress. }\end{array}$ \\
\hline $\begin{array}{l}\text { Evaluation } \\
\text { outcomes }\end{array}$ & $\begin{array}{l}\text { Evaluations of the VDDC programme in seven rural } \\
\text { NSW hospitals demonstrated a reduction in } 28 \text {-day } \\
\text { readmissions and patient sitters. }{ }^{11} \text { Caregiver and staff } \\
\text { reported improved patient safety, nutrition, hydration and } \\
\text { reduced patient distress. }{ }^{20} \text {. }\end{array}$ & & $\begin{array}{l}\text { Hospital readmissions } \\
\text { and duration of stay, } \\
\text { clinical mental health and } \\
\text { psychosocial outcomes. }\end{array}$ \\
\hline
\end{tabular}

NSW, New South Wales; VDDC, Volunteer Dementia and Delirium Care.

2013. MyCare provides step-down, assertive outreach support model with a dual focus of both mental health issues and psychosocial adjustment (ie, emotional, social, physical and spiritual dimensions of health) for 12-18 months for 18-64 year olds with severe mental illness. At the point of referral, a MyCare senior practitioner assesses the eligibility of the individual (ie, individuals aged 18-64 years are motivated to change). If eligible, the client is then allocated a care coordinator (formal paid health professional) who visits the client, at least once a week, and focuses on addressing whole-of-life goals including: (1) supporting the transition from hospital and back into the community, (2) increased productivity, participation and economic impact, (3) reductions in risk factors and
(4) improved financial independence. Every 13 weeks, the care coordinators complete a case review and evaluate the clients progress in attaining their desired goals. If the care coordinator identifies any deterioration in the client's recovery, a caseworker from the mental health service will provide specialised support and referral.

In 2018, the implementation and fidelity of MyCare was evaluated by several stakeholder groups (clients, staff and senior executives; O'Donnell et al, under review). The fidelity of the programme was evaluated as high with home visitations delivered weekly and timely client progress reviews completed. The stakeholders evaluated the implementation strategy of the programme as a success due to the following: tension for change in the 
community, the programme's strong evidence base and persistent engagement strategy. An effectiveness trial of MyCare is scheduled for 2021.

\section{Home-Start (R0)}

Home-Start is an early intervention programme that offers in-home support, via volunteers, to vulnerable parents of children under the age of 5 years. At the point of referral, the Home-Start coordinator makes an initial visit to the family to assess their needs. If Home-Start is deemed appropriate for the family, the coordinator then matches a volunteer to the family. Thereafter, the assigned volunteer visits the family for 4 hours once a week, over a period of 12 months. The actual content of the support that is delivered varies depending on the needs of the family and the goals they wish to achieve. The more common strategies that are delivered includes: mentoring (eg, guidance on practical parenting strategies); practical support (eg, shopping and accompanying them to appointments); positive engagement with children (eg, reading and play); emotional support (eg, providing positive reinforcement, validation, normalisation and a listening ear); and linkage into services (eg, family services, mental health services, maternal child health, supported playgroups, educational opportunities for parents and children).

A number of evaluations of Home-Start has identified positive improvements in both parental and child wellbeing outcomes. ${ }^{23}{ }^{24}$ For example, Van Aar and colleagues $(2015)^{25}$ evaluated the longitudinal impact of the HomeStart programme on mothers $(n=59)$ who had received the programme for 7 months compared with a random community sample. Ten years after the delivery of the programme, the positive changes were sustained in the intervention group that showed higher parenting competence, consistent and non-rejecting parenting behaviours as compared with the control group. Home-Start generates positive changes in the short term, but importantly, these changes are sustained over time. ${ }^{25}$

\section{Guiding framework}

A programme logic (also referred to as a theory of change, programme theory or logic model) is a model that describe the resources (inputs) and activities strategies (outputs) that make up a programme and the anticipated short, mid and long term impacts (outcomes). ${ }^{26}$ A programme logic is a useful tool for programme planning, management and evaluation ${ }^{27}$ and provides a visual representation of the programme alongside the underlying assumptions and theoretical framework. As a result, a programme logic helps provide stakeholders with the overall structure and function of a programme. ${ }^{26}$ For this project, the programme logic for each of the three successful existing programmes were used to demonstrate the programme components (inputs and outputs) to guide the creation of the MyCare Ageing programme logic and to identify anticipated outcomes for MyCare Ageing.

\section{Data collection}

After the presentation of the three programmes, the participants were divided into four groups and asked to brainstorm the programme components for MyCare Ageing and to provide a corresponding rationale of why the component was important. After each of these sessions, the project manager (EP) facilitated discussion with the whole group of attendees on the proposed programme components to attain a consensus on what should be included and excluded. Thereafter, the agreed on components of MyCare Ageing were presented back to the group who were then asked to identify the strengths, weaknesses, opportunities and threats (SWOT analysis) of the proposed programme. The project team took notes during the workshop, and the workshop was audio recorded to capture the discussions.

\section{Data analysis}

A matrix process of connecting analysis was conducted. This form of qualitative data analysis uses a similarity-based display and is constructed by creating lists of column categories (programme activities, resources and outcomes) by row categories of referral, volunteer and person with dementia and/or delirium. The display enables connections to be made across the rows and columns. ${ }^{28}$ A matrix with each of the programme components that reached consensus by workshop participants was synthesised into a programme logic by deductively identifying project inputs, outputs and outcomes. The programme logic was circulated to the project and investigator teams for feedback as to the accuracy of how programme components were classified.

\section{Workshop 2: implementation strategies for MyCare Ageing}

The objective of workshop two was to develop the MyCare Ageing implementation strategies.

\section{Recruitment}

Participants from workshop one were invited to attend and to also nominate additional colleagues who could help to inform the implementation strategies for MyCare Ageing. Email invitations were sent by the project team and investigators (EP, DA, RO and DV) to identified key stakeholders. Twenty-seven were invited to participate in a 5-hour workshop in addition to the investigators and project team.

\section{Workshop overview}

Workshop 2 commenced with introductions, a summary of workshop one including the aims of MyCare Ageing, an outline of the purpose and programme of the day and an explanation of what is implementation and how to develop implementation strategies including the process for identifying barriers and enablers. The implementation plan for each of the three existing programmesThe VDDC programme, MyCare and Home-Start-was presented by a programme representative. This was followed by an overview of Baptcare's volunteer recruitment and training processes. 


\section{Guiding framework}

The COM-B model (also referred to as the behaviour change wheel) was developed by Michie and colleagues ${ }^{29}$ in a process of synthesising 19 behaviour change theories. The COM-B model demonstrates that human behaviour (B) is the result of interactions between physical and psychological capabilities $(\mathrm{C})$ that use social and environmental opportunities $(\mathrm{O})$ via motivators $(\mathrm{M})$ that are reflective ('thinking' with the head) or automatic ('thinking' with the heart). The COM-B framework has been used extensively in implementation research to identify barriers and enablers for key stakeholders to engage in a programme. ${ }^{30-32}$ The model maps strategies to enhance implementation based on identified barriers and enablers. ${ }^{29}$ For this study, the COM-B model was used to categorise barriers and enablers to implementation as identified by the workshop participants. The process of how the analysis was conducted using the COM-B model is described below.

\section{Data collection}

The workshop participants were allocated to one of four groups based on their role and expertise:

1. Hospital volunteer training, resources and support.

2. Community volunteer training resources and support.

3. Volunteer recruitment, selection and matching processes.

4. Hospital staff training and support, patient identification, recruitment and matching to volunteer.

Each group was provided with an implementation template (see online supplemental appendix 1) with columns for activities (processes, logistics, actions and strategies), responsibilities (who and when), expected impact (what) and evaluation methods (how do we measure impact). Each group was provided with a description of the COM-B model and were asked to identify barriers and enablers to the implementation of MyCare Ageing. The project team took notes during the workshop and the workshop was audio-recorded to capture discussions.

\section{Data analysis}

The implementation templates and barriers and enablers notes were analysed with additional information added from the transcript of the audio recording. Barriers and enablers were identified in a process of deductive content analysis using the COM-B model to structure and operationalise the analysis. ${ }^{33}$ A categorisation matrix was developed with the column categories of capability barriers, capability enablers, opportunity barriers, opportunity enablers, motivation barriers and motivation enablers and row categories of hospital volunteers, community volunteers, recruitment and matching, hospital staff. ${ }^{33}$ Three researchers were involved in the process of deductive coding (EP, DA and RO). The barriers and enablers identified were presented to the project team and investigator team for feedback on accuracy and refinement.
Patient and public involvement

Patient and public involvement in the co-design of MyCare Ageing occurred with a consumer representative participating in both codesign workshops. Patients and the public were not involved formally in data analysis or interpretation.

\section{Rigour}

Credibility was enhanced by participant and researcher triangulation with multiple stakeholders with different experiences and perspectives being represented among the investigator team and co-design workshop participants. Data collated from the workshops were across a variety of sources including templates completed by participants, notes by researchers and audio-recordings. Additionally, workshop summaries were emailed to all participants to check interpretations and final decisions. The codesign workshop process and findings have been presented at research and clinical forums.

\section{RESULTS}

\section{Overview of workshop participants}

Workshop one had 19 participants and workshop two had 18 participants. Participants were programme developers, implementation experts, a consumer, clinicians and allied health, hospital staff, Baptcare staff, researchers, investigators and project staff.

Through the codesign workshops, a programme logic and implementation strategies for MyCare Ageing was developed.

\section{Workshop 1 results: identification of MyCare Ageing programme components}

Participants in workshop 1 agreed on the following volunteer activities to include in MyCare Ageing:

- The volunteer will assist in the development of the patient personal profile, which documents patient preferences for activities (eg, reading, conversation and music) and person-centred goal setting for care with the patient, caregivers and hospital staff.

- Based on the patient profile, the volunteer will engage the person in these activities, provide practical and emotional support, orient the person (time, day and where they are), be a patient advocate, assist in communicating patient needs to the medical team and review patient goals and achievements regularly.

- Volunteers will provide practical support for the patient by promoting the use of visual and hearing aids and encouraging walking if safe to do so by hospital staff.

- The volunteers would be aware of transition planning and will provide information, education and access to community support services as required.

- The participants agreed that since the volunteer will be trained specifically in how to care for a person with dementia and/or delirium, they could model engagement and care strategies to family and friends 


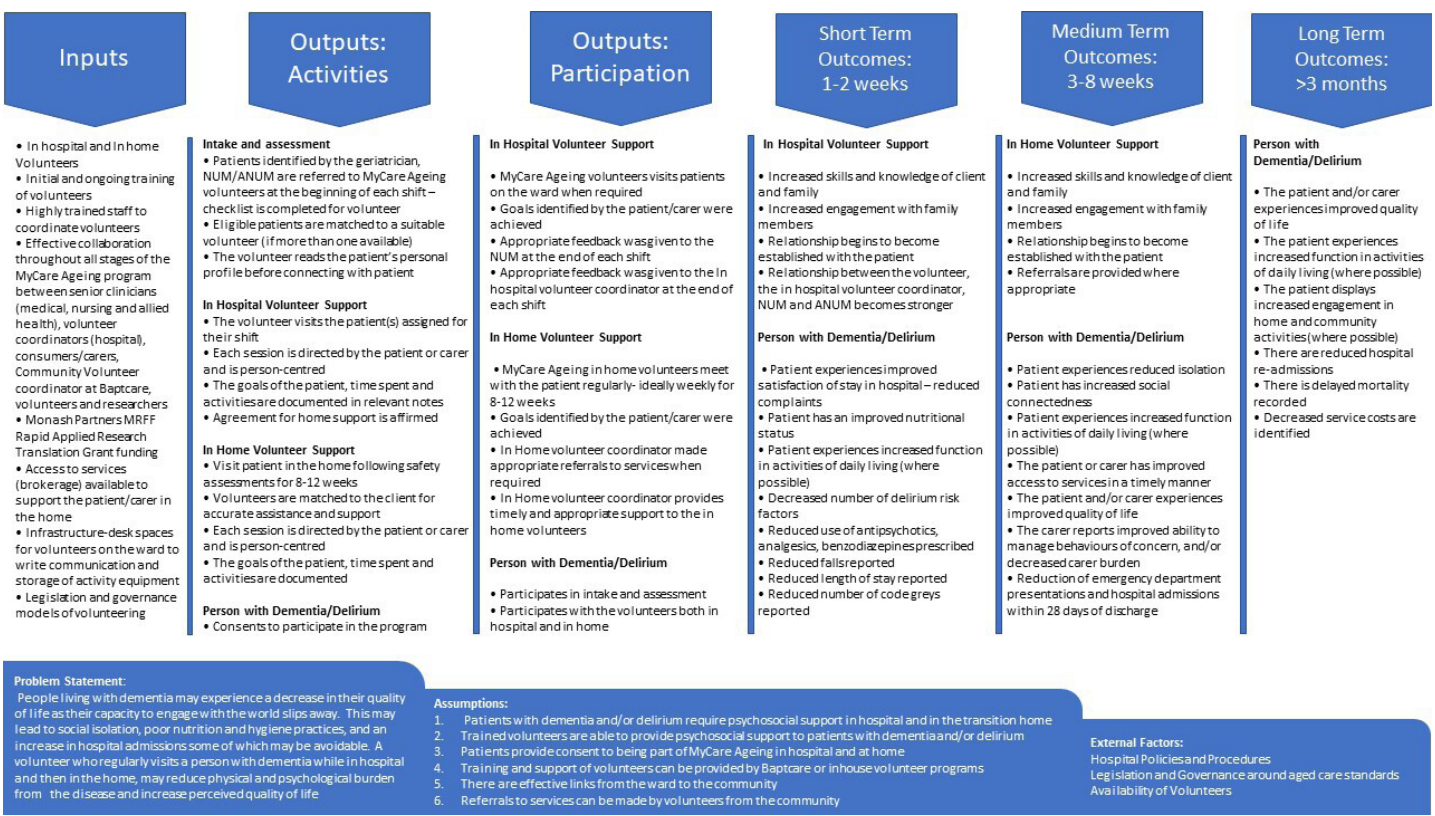

Figure 1 MyCare Ageing programme logic here.

as appropriate. Participants recognised that the volunteers would require ongoing training.

Programme components that participants felt required further consideration related to practical supports. For example, the different health services had varying policies on the level of assistance a volunteer could provide for nutrition and hydration. One health service specified that the volunteers could set up meals (unwrapping food, opening containers and cutting up food), ensure food and drink is nearby and put the utensils into the person's hands. No food-to-mouth feeding by volunteers was permitted. Another health service did allow food to mouth feeding by volunteers if they had gone through appropriate training.

After workshop 1, it was decided that the volunteers should be two separate groups-one group specifically for hospitals and one for the community home visitation. The reason for this was that two of the hospitals had existing volunteer programmes for patients in the hospital. The hospital staff felt that it was a better use of resources to use these existing hospital volunteers for the hospital component and use the MyCare Ageing volunteers for the transition home support component. Figure 1 details the programme logic for MyCare Ageing and table 3 outlines the SWOT analysis.

\section{Workshop 2 results: implementation strategies for MyCare Ageing}

The participants in workshop 2 worked in four groups to develop an implementation plan for MyCare Ageing: volunteer recruitment, training and matching to the patient, hospital-based volunteers, community-based volunteers and hospital staff training and engagement. The implementation findings from this workshop are summarised below and are referenced to the COM-B model (ie, capability, opportunity and motivation). Furthermore, these findings are summarised in table 4 .

Volunteer recruitment, training and matching to patient

- A diverse recruitment strategy via churches, university students, cultural groups and sporting groups was outlined as an opportunity enabler to recruit a diversity of volunteers in terms of age, gender, cultural background and interests.

- Informal interviews and formal reference checks would be conducted.

- Volunteers would need to have the appropriate police and working with children checks.

- Training for volunteers (capability enabler) could be for both the hospital and community volunteering and then volunteers could decide if they wanted to volunteer in one or both settings.

- Hospital volunteers would need to attend the hospitalspecific volunteer training and induction.

- The process of matching the volunteer to the patient would involve the patient, volunteer and volunteer coordinator; however, it was recognised that how this is done would be potentially different at each site.

- A webpage for volunteers to access resources and support and to collate stories from current volunteers about the benefits and opportunities of becoming a volunteer was recommended as a capability enabler.

- Volunteers should not have experienced a recent loss (defined as in the last 12 months), particularly if the volunteer's loved one passed away in hospital and the volunteer wants to work in the hospital setting; this was identified as a motivation barrier.

- Emphasis needs to be on the value for the patient and also the reciprocity of experience highlighting the benefits for the volunteer in terms of being trained, 
Table 3 SWOT analysis of the MyCare Ageing programme

\section{Strengths}

Patient:

- Provide person-centred support.

- Expands support system especially for vulnerable population.

- Reduce anxiety and stress for patients.

- Reduce patient loneliness when transitioning home.

- Opportunity for social connection.

Volunteers:

- Enriching and meaningful experience for volunteers.

- Skill development for volunteer.

- Volunteers part of the team.

Hospital:

- Addresses an identified gap.

- Cost reduction in hospital.

- Preventing avoidable remissions.

- Free up allied health staff/clinicians time on ward.

- Reduce hospital staff burden.

- Increased awareness of dementia and delirium.

- Could facilitate early discharge.

Programme design:

- Novel.

- Mutually beneficial relationship between volunteer and client.

- Proactive and preventive.

- Positive benefits for volunteers and clients.

- Early intervention provided.

Opportunities
Patient:
Patient may be able to stay at home for longer.
Vositive outcomes for families.
Volunteer:
Training.
Educating community - reduce stigma regarding cognitive
impairment.
Volunteer drives programme.
- Volunteer support plan.
Hospital:
Reduce burden in healthcare system.
Provide best practice care in hospitals.
Reinvestment cost saving - financially sustainable.
- Expanding to aged care facilities.
- Eapacity building in the community.
Expansion to other hospitals.
Grant to allow paid worker (ie, two-tier approach).
Develop strong safety framework.
- Linkage with community services.

\section{Opportunities}

Patient:

Patient may be able to stay at home for longer.

Volunteer:

Training.

Volunteer drives programme.

- Volunteer support plan.

Hospital:

Reduce burden in healthcare system.

- Reinvestment cost saving - financially sustainable.

- Expansion to other hospitals.

- Grant to allow paid worker (ie, two-tier approach).

Linkage with community services.

Role playing as part of training.

\section{Weaknesses}

Patient:

Patient confidentiality.

Volunteers:

- Recruitment and turnover - filling gap during transitions.

- Ongoing support volunteers and consultation/supervision.

- Crisis training required for volunteers.

- Travel for volunteers - geographic catchments.

- Large time commitment.

- Lack of continuity of volunteers.

- Variation and unstandardized approach of volunteers.

- Not having immediate professional support for volunteers.

- Volunteers are not paid so consideration of specific training and not asking too many demands of the volunteers is required.

- Clarity surrounding the role of the volunteer - home based and hospital based?

- Boundaries of volunteers.

- Uncertainty of recruitment.

- Matching of volunteers to patients.

- Need safety and risk assessment.

- Overlap or competition with other hospital-based volunteer programmes.

\section{Threats}

- Turnover of volunteers.

- High population of cognitive impairment.

- Occupational health and safety - unpredictable behaviours, behavioural and psychological symptoms of dementia and safety in the house.

- Elder abuse - volunteers may identify this is occurring need to determine how will this be managed.

- Measurement of outcomes will be difficult (eg, readmission rate).

- Degree to which readmission is considered a failure for the programme.

- Securing consent of participants.

- Integrating different volunteer groups.

- Staff acceptance.

- Risk factors (eg, home).

- Adequate resources.

- Volunteer regulation and legislation.

- Baptcare managing volunteers - possibility of communication challenges.

- Volunteers need to be self-motivated, reliable, independent, honest, thick-skinned and compassionate.

- Volunteers should not have experienced a recent loss. work experience and social connection as motivation enablers.

Hospital staff training, engagement and dissemination of information

- Highlight reductions in the workload of paid staff is a motivation enabler. The programme needed to be pitched as 'The MyCare Ageing program volunteers will free up your time so you can add optimal value with your professional skill set'.

- Launch the idea of MyCare Ageing on the wards to get everyone on board before beginning the programme.

- A programme champion for each ward was identified as a key opportunity and motivation enabler and implementation strategy. 
Table 4 Barriers and enablers to the implementation of MyCare Ageing guided by the COM-B model

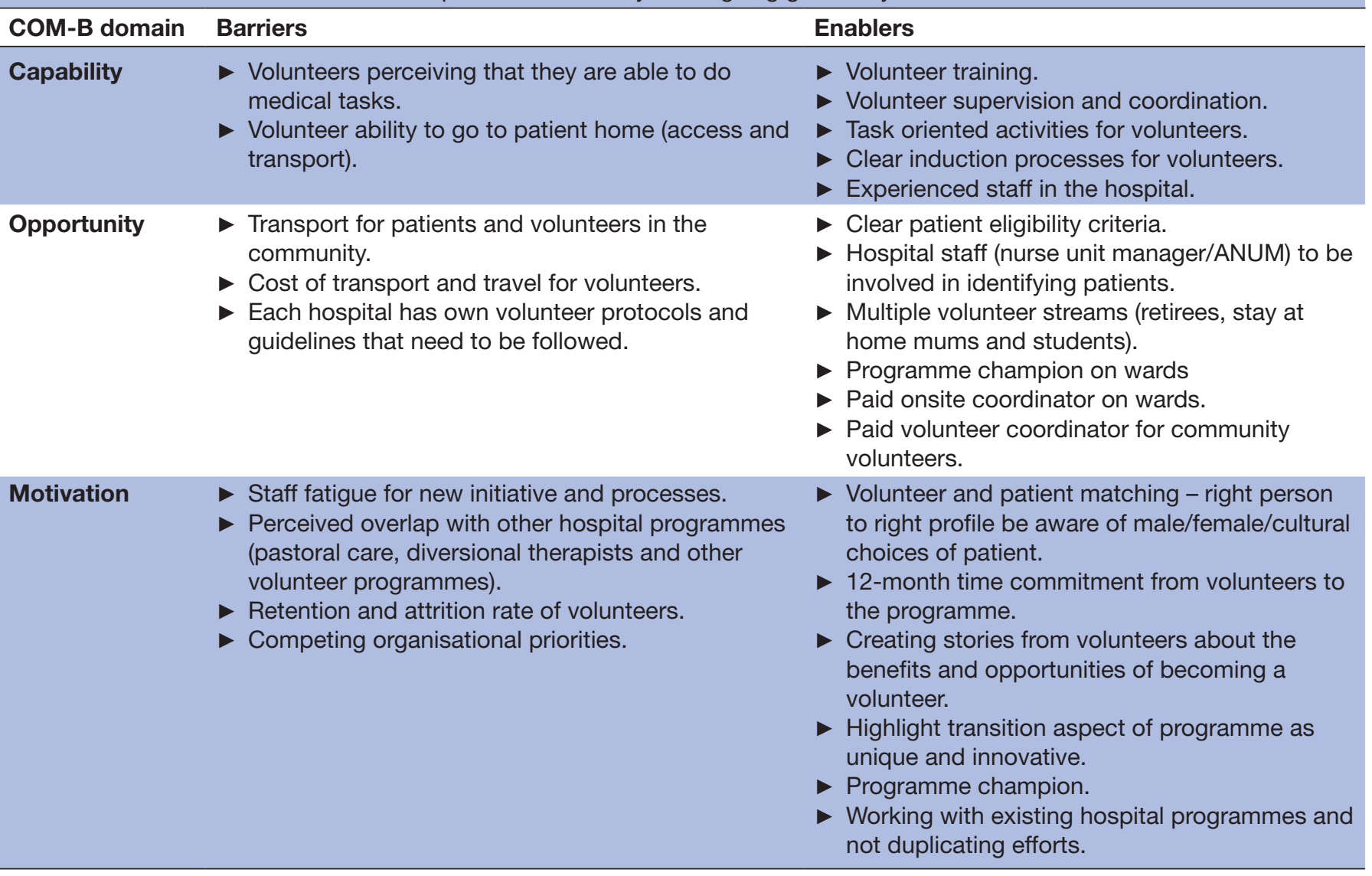

ANUM, Assistant Nurse Unit Manager.

- Linking MyCare Ageing with other initiatives on the ward and organisational priorities was seen as an opportunity enabler strategy to gain traction for the programme.

- Providing regular feedback to staff was decided as critical to keep people engaged.

- Motivation and opportunity barriers to consider were staff fatigue with new initiatives and processes and seasonal impacts in terms of bed shutdowns.

\section{Hospital-based volunteers}

- Tailor implementation to each hospital site to incorporate site-specific guidelines and protocols as both an opportunity enabler and barrier (particularly important for nutrition and hydration).

- Volunteer activities need to be task oriented, and listening and emotional support were highlighted as paramount aspects of the role.

- Training (capability enabler) needs to take a common sense approach to incorporate both generic training about the organisations (Baptcare and the hospital) and specific information relevant to the programme role (dementia and delirium, appropriate volunteer activities and patient confidentiality).

- Assistant nurse unit manager would be the best person on the ward to identify patients for the programme as they would be aware of all the patient's needs on the ward and would be easier to access than the nurse unit manager.

- Paid project lead on each site funded 1 day a week is required to assist with the implementation of the project.

- There is a need to be respectful of existing volunteer programmes at the hospital and to work with these and not in competition as an opportunity enabler. For example, if a dementia/delirium volunteer programme was established at the hospital, MyCare Ageing could offer volunteers for the transition home component of the programme as a value-add component.

\section{Community-based volunteers}

- There is a need for volunteer training and orientation, risk assessment, communication processes, patient information and resources, and privacy and confidentiality as capability enablers.

- Centralised training and support system is considered ideal.

- The programme must have clear induction processes for volunteers with boundaries in place for the activities, time spent with the patient, safety procedures and completion of services. 
- A volunteer coordinator at Baptcare should be a required paid role (opportunity enabler). Participants believed that the volunteer coordinator from Baptcare needs to complete a risk assessment at the patient's home before the volunteer's first visit. An ideal process identified was for the home volunteer to meet with the patient, family/friend and hospital volunteer in the hospital to help with the transition home and sharing of relevant patient information.

- Clear reporting pathways for escalating any patient health issues identified by the volunteer are highlighted. A proposed pathway was for the volunteer to inform the volunteer coordinator who would then contact the nominated person (family/friend) for the patient.

- A communication pathway for volunteers, which included strategies for debriefing and processes for the volunteer coordinator to communicate with the volunteer, is required. iPads were identified as a resource for volunteers to have to provide games for the patient and information to the volunteer. The potential for the iPad to have a panic button message system as a safety mechanism was also discussed.

- A motivation barrier to address is accessing and the cost of transport for patients and volunteers once in the community.

\section{DISCUSSION}

We have used a codesign approach to design the MyCare Ageing programme to provide psychosocial support by volunteers for older adults with dementia and/or delirium as they transition from hospital to home. Participants in this study represent a range of stakeholders including clinicians, hospital volunteer coordinators, representatives from BaptCare, researchers, health service senior staff and a consumer. This programme represents a unique and innovative approach to addressing the social and practical challenges older adults with dementia and/ or delirium or risk of delirium face when transitioning from hospital to home. ${ }^{5}$ To date, there are no volunteerbased programmes that provide transition support for these patients in Victoria.

\section{The value of adopting a codesign process in developing the MyCare Ageing}

We adopted a codesign approach to the development of the MyCare Ageing programme as we recognised the complexity of the programme and valued the collaborative production of knowledge with researchers working with key stakeholders. ${ }^{34}$ An important aspect was identifying the key stakeholders and building partnerships with them to ensure the acceptability and support of the proposed MyCare Ageing programme. The value of this approach was demonstrated when several stakeholders from different hospital sites highlighted that feeding patients was not a role a volunteer could do as per their hospital guidelines. If MyCare Ageing had been developed purely by researchers, feeding at all sites may have been included, which would have compromised programme implementation. Previous studies have also identified the gap between the practical bottom-up knowledge of nonacademic stakeholders when compared with the top-down scientific expert knowledge ${ }^{35}$ and how codesign offers the benefits of different perspectives in the development of services and programmes. ${ }^{36}$

\section{Recognising that one size does not fit all}

The MyCare Ageing programme was developed from previous programmes-MyCare, Home-Start and the VDDC programme. Building on preimplementation work in these previous programmes, the codesign study emphasised the importance of a tailored approach for each of the sites and the community setting of volunteers. Workshop participants identified barriers and enablers to implementation that were analysed as per the COM-B framework. The use of the COM-B framework facilitates the design of implementation strategies to address the barriers. ${ }^{29}$ This analysis highlighted that not only did the programme components need to be tailored to the sites, implementation strategies including training, resourcing and communication processes between volunteers, coordinators and hospital staff needed to be site specific. The importance of tailoring interventions and implementation strategies has been described in the literature in both theoretical $^{3738}$ and empirical ${ }^{3940}$ studies.

\section{Challenges and limitations}

Codesign is a time-intensive process. ${ }^{41}$ The workshops for this project were separated by approximately a month to enable the research team to analyse the results from workshop 1 and to design the processes for workshop 2. The workshop participants were consulted to refine and further develop locally relevant implementation strategies, which was time-consuming for the stakeholders. Identification of the stakeholders and inviting individuals from different sectors (hospitals, community, research and consumers) did take some logistical creativity to ensure we had appropriate representation from the different groups, taking into consideration time constraints and costs for people to attend.

\section{Strengths}

A strength of this study was the adoption of a codesign process to develop the intervention via genuine engagement with clinicians, community stakeholders, hospital staff and consumers. This led to strong stakeholder support and ownership of the MyCare Ageing programme illustrated by the high retention of participants across the two workshops. These stakeholder groups will be engaged for the remaining action research steps (see table 1 for steps 3-7) of the project and are reflected in the authorship of this paper. The involvement of a consumer in both workshops was valuable and upheld the principle of consumer and community involvement in research. The research team consisted of strong and experienced workshop facilitators who were able to negotiate different 
perspectives and ensured that all voices in the room were heard during the activities and discussions.

\section{Next steps and future research}

The MyCare Ageing programme is currently being piloted in one ward in three hospitals in metropolitan Melbourne. The pilot includes a mixed-methods process evaluation embedded within the implementation. The process evaluation will capture data on implementation fidelity (was MyCare Ageing implemented as planned and how was it tailored to wards) and acceptability and feasibility from the perspective of volunteers, patients, caregivers, hospital staff and volunteer coordinators. The process evaluation will examine the barriers and enablers and the SWOT analysis to determine whether what was anticipated or expected occurred in reality. The implementation and process evaluation will inform a future randomised controlled trial, which will establish effectiveness.

\section{CONCLUSION}

The codesign process was successfully applied to develop the MyCare Ageing programme to provide volunteer support to patients with dementia and/or delirium in hospital and in the transition home. The programme components of MyCare Ageing were adapted from three evidence-based programmes-VDDC programme, HomeStart and MyCare. The involvement of stakeholders across the hospital, community and academic settings generated site-specific tailored and relevant programme components and implementation strategies. MyCare Ageing is an innovative programme that meets an identified need from hospitals and consumers to support patients with dementia and/or delirium to improve psychosocial outcomes on discharge from hospital.

\section{Author affiliations \\ ${ }^{1}$ Monash Centre for Health Research and Implementation, Monash University, Melboune, Victoria, Australia \\ ${ }^{2}$ Department of Epidemiology and Preventive Medicine, Monash University, Melbourne, Victoria, Australia \\ ${ }^{3}$ Victoria Family \& Community Services Service \& Operations, Baptcare, Melbourne, Victoria, Australia \\ ${ }^{4}$ Southern New South Wales Local Health District, Queanbeyan, New South Wales, Australia \\ ${ }^{5}$ Peninsula Clinical School, Monash University, Frankston, Victoria, Australia \\ ${ }^{6}$ Rehabilitation and Aged Care Services, Monash Health, Clayton, Victoria, Australia ${ }^{7}$ Rehabilitation, Aged and Community Care, Alfred Health, Melbourne, Victoria, Australia \\ ${ }^{8}$ Department of Aged Care Services, Alfred Health, Melbourne, Victoria, Australia ${ }^{9}$ University of Warwick, Coventry, UK}

Acknowledgements We would like to thank all the participants of the workshop for providing their time and expertise in the design of MyCare Ageing. We would also like to thank Larkin Lamarche for his thoughtful and constructive review of this manuscript.

Contributors Study conceptualisation: DA, HS and DV. Data curation: DA, RO, EP, HM, MS, CM, JB-H, JL, SP, VKS, CB and PH. Formal analysis: DA, RO, HM and MS. Funding acquisition: HS, DA, DV, VS, CM, JB-H and JL. Investigation: DA, HS, DV, VS, CM, JL, JB-H, SP and PH. Methodology: DA, HS, DV, VS, CM, JL, JB-H, SP and PH. Project administration: HM, EP, MS and DA. Resources: HS, DV and DA. Drafting of the manuscript: DA, RO, HM, MS and HS, Review, revisions and approval of the manuscript: all authors.

Funding This study was supported by Medical Research Future Fund Monash Partners Rapid Applied Health Services Research Grant.

Competing interests None declared.

Patient and public involvement Patients and/or the public were involved in the design, or conduct, or reporting, or dissemination plans of this research. Refer to the Methods section for further details.

Patient consent for publication Not required.

Provenance and peer review Not commissioned; externally peer reviewed.

Data availability statement All data relevant to the study are included in the article or uploaded as supplementary information.

Open access This is an open access article distributed in accordance with the Creative Commons Attribution Non Commercial (CC BY-NC 4.0) license, which permits others to distribute, remix, adapt, build upon this work non-commercially, and license their derivative works on different terms, provided the original work is properly cited, appropriate credit is given, any changes made indicated, and the use is non-commercial. See: http://creativecommons.org/licenses/by-nc/4.0/.

\section{ORCID iDs}

Darshini Ayton http://orcid.org/0000-0002-2754-2024

Renée 0'Donnell http://orcid.org/0000-0003-2563-2867

\section{REFERENCES}

1 Powers BW, Milstein A, Jain SH. Delivery models for high-risk older patients: back to the future? JAMA 2016;315:23-4.

2 Cheek J, Ballantyne A, Roder-Allen G. Factors influencing the decision of older people living in independent units to enter the acute care system. J Clin Nurs 2005;14 Suppl 1:24-33.

3 Lowthian JA, Curtis AJ, Jolley DJ, et al. Demand at the emergency department front door: 10-year trends in presentations. Med J Aust 2012;196:128-32.

4 Searle SD, Rockwood K. What proportion of older adults in hospital are frail? Lancet 2018;391:1751-2.

5 Andreasen J, Lund $\mathrm{H}$, Aadahl M, et al. The experience of daily life of acutely admitted frail elderly patients one week after discharge from the hospital. Int J Qual Stud Health Well-being 2015;10:27370.

6 Conroy SP, Ansari K, Williams M, et al. A controlled evaluation of comprehensive geriatric assessment in the emergency department: the 'Emergency Frailty Unit'. Age Ageing 2014;43:109-14.

7 Craswell A, Marsden E, Taylor A, et al. Emergency Department presentation of frail older people and interventions for management: Geriatric Emergency Department Intervention. Safety in Health 2016;2.

8 Morse L, Xiong L, Ramirez-Zohfeld V, et al. Tele-Follow-Up of older adult patients from the geriatric emergency department innovation (GEDI) program. Geriatrics 2019;4. doi:10.3390/geriatrics4010018. [Epub ahead of print: 29 Jan 2019].

9 Hwang U, Dresden SM, Rosenberg MS, et al. Geriatric Emergency Department Innovations: Transitional Care Nurses and Hospital Use. J Am Geriatr Soc 2018;66:459-66.

10 Bateman C, Anderson K, Bird M, et al. Volunteers improving personcentred dementia and delirium care in a rural Australian hospital. Rural Remote Health 2016;16:3667.

11 Blair A, Anderson K, Bateman C. The "Golden Angels": effects of trained volunteers on specialling and readmission rates for people with dementia and delirium in rural hospitals. Int Psychogeriatr 2018;30:1707-16.

12 Inouye SK, Bogardus ST, Baker DI, et al. The hospital elder life program: a model of care to prevent cognitive and functional decline in older hospitalized patients. Hospital elder life program. J Am Geriatr Soc 2000;48:1697-706.

13 Caplan GA, Harper EL. Recruitment of volunteers to improve vitality in the elderly: the revive study. Intern Med J 2007;37:95-100.

14 Hotchkiss RB, Fottler MD, Unruh L. Valuing volunteers: the impact of volunteerism on hospital performance. Health Care Manage Rev 2009;34:119-28.

15 Hirschman KB, Hodgson NA. Evidence-Based interventions for transitions in care for individuals living with dementia. Gerontologist 2018;58:S129-40.

16 Osborne SP, Radnor Z, Strokosch K. Co-Production and the cocreation of value in public services: a suitable case for treatment? Public Management Review 2016;18:639-53. 
17 Batalden M, Batalden P, Margolis P, et al. Coproduction of healthcare service. BMJ Qual Saf 2016;25:509-17.

18 Lwembe S, Green SA, Chigwende J, et al. Co-production as an approach to developing stakeholder partnerships to reduce mental health inequalities: an evaluation of a pilot service. Prim Health Care Res Dev 2017;18:14-23.

19 Agency for Clinical Innovation. Volunteer dementia and delirium care implementation and training resource, 2019. Available: https://www. aci.health.nsw.gov.au/resources/aged-health/confused_hospitalised older_persons/dementia-and-delirium-care-implementation-training

20 Blair A, Bateman C, Anderson K. "They take a lot of pressure off us": Volunteers reducing staff and family care burden and contributing to quality of care for older patients with cognitive impairment in rural hospitals. Australas J Ageing 2019;38 Suppl 2:34-45.

21 Ayton D, Moran C, Berkovic D, et al. The Volunteer Dementia and Delirium Care (VDDC)(: A pre-implementation study exploring perceived acceptability to implementing the program in an acute and subacute metropolitan hospital. Australas J Ageing 2019;16.

22 Ayton D, Moran C, Berkovic D, et al. The Volunteer Dementia and Delirium Care $(\mathrm{VDDC})^{\odot}$ program: An exploration of perceived barriers and enablers to implementation in an acute and subacute metropolitan hospital. Australas J Ageing 2019;59.

23 Hermanns JMA, Asscher JJ, Zijlstra BJH, et al. Long-Term changes in parenting and child behavior after the Home-Start family support program. Child Youth Serv Rev 2013;35:678-84.

24 Smallegange ES, Hermanns JMA, Oort FJ. Evaluating the effectiveness of combining Home-Start and triple $\mathrm{P}$ parenting support in the Netherlands. Child Youth Serv Rev 2016;68:178-86.

25 van Aar JV, Asscher JJ, Zijlstra BJH, et al. Changes in parenting and child behavior after the home-start family support program: a 10year follow-up. Child Youth Serv Rev 2015:53:166-75.

26 Centre for Epidemiology and Evidence. Developing and Using Program Logic: A Guide. In: Evidence and evaluation guidance series. Sydney: Population and Public Health Division, NSW Ministry of Health, 2017.

27 Dykeman M, Maclntosh J, Seaman P, et al. Development of a program logic model to measure the processes and outcomes of a nurse-managed community health clinic. J Prof Nurs 2003;19:197-203.

28 Maxwell JA, Miller BA. Chapter 22: Categorizing and connecting strategies in qualitative data analysis. In: Hesse-Biber SN, Leavy P, eds. Handbook of emergent methods. New York City: Guilford Publications, 2008.
29 Michie S, van Stralen MM, West R. The behaviour change wheel: a new method for characterising and designing behaviour change interventions. Implement Sci 2011;6:42.

30 Barker F, Atkins L, de Lusignan S. Applying the COM-B behaviour model and behaviour change wheel to develop an intervention to improve hearing-aid use in adult auditory rehabilitation. Int $J$ Audiol 2016;55 Suppl 3:S90-8.

31 Alexander KE, Brijnath B, Mazza D. Barriers and enablers to delivery of the healthy Kids Check: an analysis informed by the theoretical domains framework and COM-B model. Implement Sci 2014;9:60.

32 Handley MA, Harleman E, Gonzalez-Mendez E, et al. Applying the COM-B model to creation of an IT-enabled health coaching and resource linkage program for low-income Latina moms with recent gestational diabetes: the StAR MAMA program. Implement Sci 2016;11:73.

33 Elo S, Kyngäs $\mathrm{H}$. The qualitative content analysis process. $J$ Adv Nurs 2008;62:107-15.

34 Greenhalgh T, Jackson C, Shaw S, et al. Achieving Research Impact Through Co-creation in Community-Based Health Services: Literature Review and Case Study. Milbank Q 2016;94:392-429.

35 Yokota F, Biyani M, Islam R, et al. Lessons learned from Co-Design and Co-Production in a portable health clinic research project in Jaipur district, India (2016-2018). Sustainability 2018;10:4148.

36 Steen M, Manschot M, De Koning N. Benefits of co-design in service design projects. International Journal of Design 2011;5:53-60.

37 Damschroder LJ, Aron DC, Keith RE, et al. Fostering implementation of health services research findings into practice: a consolidated framework for advancing implementation science. Implement Sci 2009;4:50.

38 Powell BJ, Beidas RS, Lewis CC, et al. Methods to improve the selection and tailoring of implementation strategies. J Behav Health Serv Res 2017:44:177-94.

39 Harshbarger C, Simmons G, Coelho H, et al. An empirical assessment of implementation, adaptation, and tailoring: the evaluation of CDC's national diffusion of VOICES/VOCES. AIDS Educ Prev 2006;18:184-97.

40 Jäger C, Steinhäuser J, Freund T, et al. Process evaluation of five tailored programs to improve the implementation of evidence-based recommendations for chronic conditions in primary care. Implement Sci 2016;11:123.

41 Ward ME, De Brún A, Beirne D, et al. Using Co-Design to develop a collective leadership intervention for healthcare teams to improve safety culture. Int J Environ Res Public Health 2018;15:1182. 